\title{
Surgical Treatment of Acquired Atresia of the External Auditory Ear Canal
}

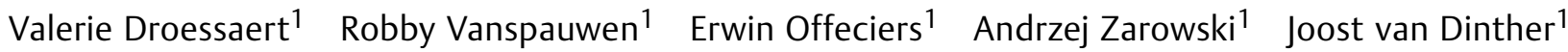 \\ Thomas Somers ${ }^{1}$
}

1 Department of ENT, European Institute for ORL, Wilrijk, Antwerp, Belgium

Address for correspondence Valerie Droessaert, MD, Department of ENT, European Instutue for ORL, Oosterveldlaan 24, Wilrijk, Antwerp

Int Arch Otorhinolaryngol 2017;21:343-346. 2610, Belgium (e-mail: valeriedroessaert@gmail.com).

\begin{abstract}
Introduction Acquired atresia of the external auditory canal is characterized by the formation of fibrous tissue in the medial part. The causes include chronic otitis externa, perforated chronic otitis media, postoperative or idiopathic healing problems. Acquired atresia presents with hearing loss and can be associated with otorrhea.

Objective We analyzed the results of surgery after six months and two years by checking (1) pre- and postoperative hearing thresholds; (2) presence of otorrhea; and (3) whether a dry and patent ear canal is achieved.

Methods We conducted this retrospective study at a tertiary referral center. In total, 27 ears underwent treatment with resection of the fibrotic plug followed by transplantation of a split-thickness skin graft covering the bare bone and tympanic membrane. When necessary, we combined this with a myringoplasty and a (meato-) canalplasty.

Results Otorrhea was present in $59.3 \%$ of the patients initially and in $14.8 \%$ at six months and $11 \%$ at two years postoperative. A dry and patent ear canal was obtained in $55.6 \%$ after six months and in $89 \%$ of the patients after two years $(n=27)$. The pure tone average before surgery was $39.1 \mathrm{dBHL}(\mathrm{SD}=20 \mathrm{dBHL}$ ), at six months $31.4 \mathrm{dBHL}$ $(\mathrm{SD}=16.4 \mathrm{dBHL})$, and at 24 months postop $30.9 \mathrm{dBHL}(\mathrm{SD}=17.1 \mathrm{dBHL})$. We

Keywords

- ear canal

- disease management

- treatment outcome

- hearing loss

- adult observed a statistically significant improvement of hearing in $63 \%$ of the patients at six months $(p=0.005)$ and in $65 \%$ after two years $(p=0.022)$.

Conclusions Treatment of acquired atresia remains a challenge. Using the appropriate surgical technique, including skin-grafting and regular postoperative check-up, rendered excellent results regarding otorrhea and a moderate improvement of hearing was achieved in $65 \%$ of the patients after two years.
\end{abstract}

\section{Introduction}

Acquired atresia of the external auditory canal is a rare condition in which the medial part of the ear canal is blocked by a fibrotic plug. ${ }^{1}$ It is usually caused by recurrent infections or inflammation with formation of granulation tissue. Recurrent inflammation leads to accumulation of fibrotic scar tissue and lateral extension of this fibrotic plug toward the cartilaginous junction in the external auditory canal (EAC). Other causes include: healing problems, fibrosis after surgery, radiotherapy, trauma, dermatologic conditions, neoplasm, or idiopathic. ${ }^{2-7}$ Acquired atresia may be combined with EAC cholesteatoma. Major patient complaints include otorrhea and hearing loss.

Paparella et al described the surgical technique to treat acquired atresia $a s^{8}$ : removal of the fibrotic plug and the received

May 26, 2016

accepted

November 6, 2016

published online

February 28, 2017
DOI https://doi.org/

10.1055/s-0037-1598604. ISSN $1809-9777$.
Copyright $\odot 2017$ by Thieme Revinter

Publicações Ltda, Rio de Janeiro, Brazil
License terms

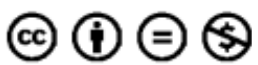


diseased skin with a maximal widening of the bony canal and meatus, followed by grafting of the bare areas with a split thickness skin graft.

We analyzed the surgical results 6 and 24 months after surgery in a series of acquired atresia, comparing (1) the hearing before and after surgery, (2) the presence or absence of otorrhea, and (3) the anatomical result. An anatomical success means a dry and patent external ear canal, that is, the absence of otorrhea, myringitis, granulation formation, or tendency to restenosis.

\section{Materials and Methods}

\section{Study Population}

We performed this study at a tertiary referral center. We retrospectively analyzed patient records of acquired atresia surgery (canalplasty and grafting) performed between 2009 and 2014. We collected the following data: age, sex, cause of atresia, presenting symptoms (otorrhea, hearing loss) and otoscopic findings such as myringitis, fibrosis, granulation, blunting, stenosis, and atresia. We performed audiometry before and after surgery at 6 months (range: 6-12 months) and at 2 years (range: $18-30$ months). We excluded from the study patients in whom we encountered and who underwent operation for preoperatively ossicular chain pathology. In our study population, some patients suffered from middle ear pathology, but did not undergo operation for it at the first stage.

In total, we analyzed 27 ears (25 patient records, two patients needing surgery on both ears). Nine were primary cases (33\%) and 18 ears were revision cases (66\%). The mean age of the patients at the time of surgery was 27 years old (range: 9-61y). The sex ratio was 13 women and 14 men. Demographic data are shown in - Table 1.

\section{Surgical Technique}

The surgery is performed via a retro-auricular or endaural incision. An incision lateral to the atresia is made and the fibrosis is resected, the skin covering the fibrotic plug is preserved and kept attached to the canal skin for later canal coverage. When removing the fibrotic plug at the medial end of the EAC, one pays attention to maintain the pars fibrosa of the tympanic membrane intact and then carefully dissects by blunt dissection. In case of an ear drum perforation, a myringoplasty is performed. In the presence of a narrow

Table 1 Patient demographics

\begin{tabular}{|l|l|}
\hline & $\mathbf{N}=\mathbf{2 7}$ \\
\hline Men vs women & $52 \%$ versus 48\% \\
\hline Mean Age & 27 years (range: $9-61)$ \\
\hline Revision surgery & $18(67 \%)$ \\
\hline Follow-up time & $\begin{array}{l}6 \text { months (range 6-12 months) } \\
\text { and } 24 \text { months (18-30 months) }\end{array}$ \\
\hline Otorrhea & $59 \%$ \\
\hline Hearing loss & $74 \%$ \\
\hline
\end{tabular}

meatus and a narrow bony, a combined meatocanaloplasty is performed. The surgery aims for complete resection of the fibrosis to reduce the risk of recurrence. The anterior angle is most at risk, certainly in the case of incomplete visualization. Therefore, the surgeon establishes a broad straight external ear canal by widely drilling the canal (canalplasty) and opening the anterior sulcus angle to prevent blunting. Care is taken not to violate the temporomandibular joint anteriorly and the mastoid cells posteriorly. Inferiorly a larger amount of bone can be drilled away from the tympanic bone. The fibrotic plug resection is followed by transplantation of an ultra-thin $(0.6 \mathrm{~mm})$ split-thickness skin graft (STSG), harvested retro-auricularly using an electrical dermatome (Aesculap, Center Valley, USA). The size of the graft is evaluated using a dummy paper patch and fashioned as in the Jahrsdörfer technique for atretic ears (multiple triangular extensions at one end ensuring total tympanic coverage). Split-thickness is preferred to full-thickness grafts; the thinness of the graft ensures that the external canal will not tend to be covered with too thick skin. Attention is paid to a complete coverage of all bare bone and tympanic membrane to avoid a recurrent tendency of granulation tissue, fibrosis, and retraction. In our study, we did not perform middle ear surgery.

Packing of the ear is done using a silicon sheet which is inserted and filled with sponges embedded in an antibiotic ointment (Terra-Cortril, Zoetis, N. Jersey, USA) for at least 2 weeks. If the ear shows a tendency to restenosis at followup otoscopy, a new packing is inserted for another two weeks. Avoidance of water is crucial as long as epithelialization is not fully established. Regular follow-ups are mandatory to check for appearance of granulating areas which are treated by curetting and ototopical medication (e.g., TerraCortril, corticosteroids, Trichloroacetic acid).

\section{Statistics}

Pre- and post-operative pure tone averages (PTA), were compared using repeated measure analysis of variance (ANOVA) and pairwise post hoc comparisons (with Bonferroni correction). We performed the statistical analysis with IBM SPSS Statistics, version 23 (IBM, Armonk, NY, USA). For each analysis, we adopted a significance level of $5 \%$.

\section{Results}

In total, 27 ears of 25 patients with acquired atresia were surgically treated in the period between 2009 and 2014. The main pre-operative complaint was hearing loss in $78 \%$ of the patients. Otorrhea was reported by $59 \%$. Before surgery, micro-otoscopy revealed granulation in $100 \%$, myringitis in $7.4 \%$, and blunting or webbing in $11 \%$ of the ears. The PTA was $39.1 \mathrm{dBHL}$ (SD $20.0 \mathrm{dBHL}$ ). The causes of acquired atresia are listed in - Fig. 1, recurrent inflammation (56\%) being the most frequent cause, followed by past surgical interventions (37\%). We checked the 27 ears at 6 to 12 months and at a later mean follow-up time of 24 months (range: 18-30months) $(n=27)$. Otorrhea was still present in $14.8 \%$ of the patients at 6 months and in $11 \%$ of the patients after 24 months. At 


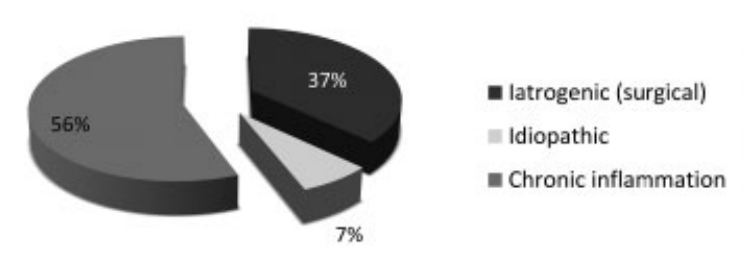

Fig. 1 Diagram showing the three etiologic causes of acquired atresia in the patient population, with inflammation being most frequent (56\%), followed by surgery (37\%), and $7 \%$ unknown cause.

6 months, 18.5\% suffered from granulation tissue and $11.1 \%$ of myringitis. At 24 months, myringitis was present in $4 \%$ and granulation tissue in $4 \%$ of the patients. In $55.6 \%$ and $89 \%$, a dry and stable condition was obtained after 6 and 24 months, respectively. At 24 months, $11 \%$ of patients presented webbing or lateralization of the tympanic membrane in the absence of otorrhea. None of our patients had revision surgery; those with persistent inflammatory areas underwent local treatment in the outpatient clinic with ear drops containing antibiotics and steroids and, if needed, with curetting of the relapsing granulation and application of Trichloroacetic acid or silver nitrate until completion of epithelial healing.

We observed a statistically significant improvement ( $F$ $(2.44)=8.5 ; p=0.003)$ of hearing when using repeated ANOVA measures. Post hoc comparisons of PTA revealed a statistically significant difference $(p=0.005)$ between preop and 6 months postop and between preop and 24 months postop ( $p=0.022$ ). The results 2 years after surgery regarding presence of otorrhea, granulation, and hearing thresholds are shown in - Fig. 2.

The mean preop PTA (mean = $39.1 \mathrm{dBHL}$; standard deviation $(\mathrm{SD})=20.0 \mathrm{dBHL}$ ) was significantly larger than the PTA measured 6 months postop $(p=0.005)$ (mean $=31.4 \mathrm{dBHL}$; $\mathrm{SD}=16.4 \mathrm{dBHL})$ and 24 months postop $(p=0.022)$ (mean $=$ $30.9 \mathrm{~dB}$ HL; SD $=17.1 \mathrm{dBHL})$. There were no statistically

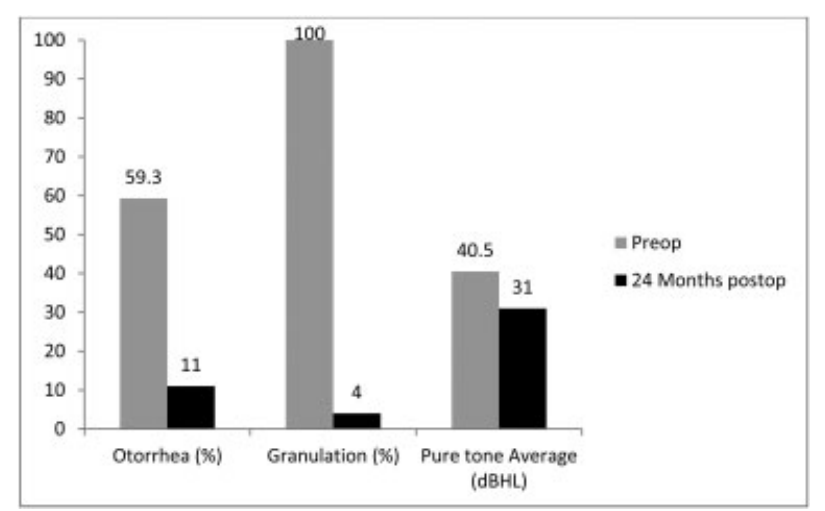

Fig. 2 Comparison of pre- and postoperative data regarding otorrhea, granulation and hearing (Pure Tone Average expressed in $\mathrm{dBHL}$ ). significant differences between the PTA measured at 6 and 24 months postop.

In $65 \%$ of the patients we obtained hearing improvement at 24 months postop, with a mean PTA of 14.3dBHL (min. 1.6; $\max 36.6$; SD 10.4).

\section{Discussion}

Acquired atresia is a rare condition and a veritable challenge to treat. Literature concerning this pathology remains scarce. ${ }^{1,9-13}$ In this retrospective study, we investigated the clinical and audiometric results.

Regarding hearing loss, we observed a moderate but statistically significant improvement with postoperative mean PTA of $9 \mathrm{dBHL}$. Comparison with data from the literature is difficult; terms such as stenosis and atresia are often mixed and patient populations are heterogenic. Atresia is the result of a process with recurrent wet episodes (active granulation) and becomes dry and stable as the cartilaginous junction has been reached. Stenosis is a pathological narrowing of the external ear canal in which the tympanic membrane might still be seen. Symptoms might differ among these different entities (primarily hearing loss in end-stage atresia versus otorrhea in stenosis). Several authors describe an improvement of hearing in $50-80 \%$ of the cases. ${ }^{1,2,9-15}$ In our study, at 24 months postop we saw a hearing improvement of $9 \mathrm{dBHL}$ in $65 \%$ of our patients, which is in line with current literature (-Table 2 ).

Incomplete healing with residual myringitis or formation of granulation tissue was present in $8 \%$ of the ears after 24 months requiring regular follow-up, suction cleaning, and curetting when needed. None of the cases required revision surgery . Our results are at the better end when compared with other published results ${ }^{1,2,9-12,14,15}$ (-Table 2).

Sixty-seven percent of the ears operated in this series were referred from elsewhere, being potentially at a higher risk for recurrence and postoperative healing problems. Eighty-nine percent of the ears remained stable with no otorrhea, but in $11 \%$, we observed webbing or lateralization of the ear drum. If webbing or lateralisation was present without otorrhoea, nothing was done and, in the absence of complaints from the patients, the situation was left as it was. We saw no statistical difference in results between revision and primary cases.

Our surgical technique is similar to the one described originally by Paparella. ${ }^{8}$ One may discuss the approach (endaural or retro-auricular) and the type of grafting (split-thickness versus full-thickness, and free graft versus pedicled vascularized graft). All authors agree that the bare areas of bone should be covered with tissues and also lined with skin grafts. Jacobson and Mills reported a $100 \%$ recurrence rate when no skin grafting was performed. ${ }^{10}$ Thus, removal of the fibrotic plug without skin grafting is doomed to fail. We prefer to use STSG as these are thin and do not tend to narrow the ear canal. A potential disadvantage of STSG could be a tendency to less favorable healing and even potential risk of necrosis, ${ }^{9}$ but the latter was not observed in our series. 
Table 2 Comparison of results regarding otorrhea, hearing improvement and recurrence rate after surgery for acquired atresia/ stenosis in literature

\begin{tabular}{|c|c|c|c|c|c|}
\hline & $\begin{array}{l}\text { Number of } \\
\text { operated ears }\end{array}$ & $\begin{array}{l}\text { Follow-up time } \\
\text { (years) }\end{array}$ & Otorrhea postop & Hearing improvement & Recurrence rate \\
\hline \multicolumn{6}{|l|}{ Present study } \\
\hline & 27 & 2 & $15 \%$ & $65 \%$ & $9 \%$ \\
\hline \multicolumn{6}{|l|}{ Literature } \\
\hline McDonald et al ${ }^{13}$ & 22 & 3.5 & $10 \%$ & $68 \%$ & $18 \%$ \\
\hline Tos \& Balle 2 & 22 & 5 & $6 \%$ & $81 \%->58 \%$ & $18 \%$ \\
\hline Cremers $\&$ Smeets $^{14}$ & 17 & 1 & $18 \%$ & $94 \%$ & $0 \%$ \\
\hline El-Sayed $^{11}$ & 12 & 2.5 & NR & $83 \%$ & $16.7 \%$ \\
\hline Becker et al ${ }^{1}$ & 53 & $4 m d-13 y$ & $7 \%$ & $51 \%$ & $11 \%$ \\
\hline Lin et $a^{12}$ & 26 & 2 & NR & $69.2 \%$ & $13.6 \%$ \\
\hline Jacobsen et al ${ }^{10}$ & 65 & 6md-6y & $21 \%$ & $79 \%$ & $21 \%$ \\
\hline Magliulo $^{15}$ & 25 & 5 & $22 \%$ & $66 \%$ & $36 \%$ \\
\hline Dhooge et $\mathrm{al}^{9}$ & 17 & 5.15 & $23.5 \%$ & $A B G:-20 d B$ & $17.6 \%$ \\
\hline
\end{tabular}

\section{Conclusion}

Acquired atresia remains a therapeutic challenge. Nonetheless, with the appropriate surgical technique and expertise, it is possible to obtain good anatomical results. In our study, we achieved moderate but statistically significant hearing improvement of $9 \mathrm{dBHL}$. Sixteen patients suffered from otorrhea preoperatively, which disappeared in $80 \%$ of these patients. We observed a patent and dry ear canal in $89 \%$ of all the ears after two years. In these ears hearing aids were applicable if necessary and water avoidance was not obligatory. The authors stress the importance of close follow-up and eventual medical ototopical treatment in the early postoperative stage to prevent recurrence of stenosis.

\section{References}

1 Becker BC, Tos M. Postinflammatory acquired atresia of the external auditory canal: treatment and results of surgery over 27 years. Laryngoscope 1998;108(06):903-907

2 Tos M, Balle V. Postinflammatory acquired atresia of the external auditory canal: late results of surgery. Am J Otol 1986;7(05): 365-370

3 Hopsu E, Pitkäranta A. Idiopathic, inflammatory, medial meatal, fibrotising otitis presenting with lichen planus. J Laryngol Otol 2007;121(08):796-799

4 Carls JL, Mendenhall WM, Morris CG, Antonelli PJ. External auditory canal stenosis after radiation therapy. Laryngoscope 2002;112(11):1975-1978
5 Demirbaş D, Dağlı M, Göçer C. Bilateral acquired external auditory canal stenosis with squamous papilloma: a case report. Kulak Burun Bogaz Ihtis Derg 2011;21(01):42-45

6 Lau DP, Goddard MJ, Bottrill ID, Moffat DA. Epithelial-myoepithelial carcinoma of the parotid gland. An unusual cause of ear canal stenosis. J Laryngol Otol 1996;110(05):493-495

7 McKennan KX, Chole RA. Traumatic external auditory canal atresia. Am J Otol 1992;13(01):80-81

8 Paparella MM. Surgical treatment of intractable external otitis. Laryngoscope 1966;76(06):1136-1147

9 Dhooge I, D'hoop M, Loose D, Acke F. Acquired atresia of the external auditory canal: long-term clinical and audiometric results after surgery. Otol Neurotol 2014;35(07): 1196-1200

10 Jacobsen N, Mills R. Management of stenosis and acquired atresia of the external auditory meatus. J Laryngol Otol 2006;120(04): 266-271

11 el-Sayed Y. Acquired medial canal fibrosis. J Laryngol Otol 1998; 112(02):145-149

12 Lin VY, Chee GH, David EA, Chen JM. Medial canal fibrosis: surgical technique, results, and a proposed grading system. Otol Neurotol 2005;26(05):825-829

13 McDonald TJ, Facer GW, Clark JL. Surgical treatment of stenosis of the external auditory canal. Laryngoscope 1986;96(08): 830-833

14 Cremers WR, Smeets JH. Acquired atresia of the external auditory canal. Surgical treatment and results. Arch Otolaryngol Head Neck Surg 1993;119(02):162-164

15 Magliulo G. Acquired atresia of the external auditory canal: recurrence and long-term results. Ann Otol Rhinol Laryngol 2009;118(05):345-349 